\title{
RECENT ADVANCES IN CALCULATING ECONOMIC INTERVENTION FREQUENCY FOR ACTIVE LEAKAGE CONTROL, AND IMPLICATIONS FOR CALCULATION OF ECONOMIC LEAKAGE LEVELS
}

\author{
A.O. Lambert ${ }^{1}$ and M. Fantozzi ${ }^{2}$ \\ ${ }^{1}$ ILMSS Ltd, 3 Hillview Close, Llanrhos, Llandudno, North Wales LL30 1SL, UK, \\ AOandJGLambert@aol.com \\ ${ }^{2}$ Marco Fantozzi, Via Forcella 29, 25064 Gussago (BS), Italy \\ marco.fantozzi@email.it ; Web:www.studiomarcofantozzi.it
}

\begin{abstract}
During the last decade, IWA Water Losses Task Force members have developed a systematic practical approach to the technical management of Non-revenue Water and its components, with (since 2002) increasing use of $95 \%$ confidence limits in these calculations. The current Water Losses Task Force (WLTF) has recently set itself an objective to develop a quick and practical method for calculating economic intervention (for active leakage control to locate unreported leaks and bursts), and short-run economic leakage level. This paper outlines a quick and practical method for assessing economic intervention frequency (and associated budgetary and volumetric parameters) for an active leakage control policy based on regular survey. Calculations are based on three key parameters: natural rate of rise of unreported leakage, marginal cost of water, and cost of intervention. It is hoped this will encourage Utilities that do not currently undertake active leakage control to adopt an ongoing basic active leakage control policy which can be simply demonstrated as being economic for their own situation. The incorporation of this methodology into software for rapid calculations of Economic Leakage Levels is at an advanced stage, and will be submitted for presentation at the next WLTF symposium 'Leakage 2005' in September 2005.
\end{abstract}

\section{KEYWORDS}

Economic intervention; economic leakage level; leakage; marginal cost; rate of rise.

\section{INTRODUCTION}

\section{Developments over the last decade.}

During the last decade, a systematic and technically robust approach to technical management of NonRevenue Water and its components has been developed and tested internationally, principally by members of IWA Task Forces. Notable steps along the way have been:

- 1994: BABE (background and burst estimates) concept for analysis and prediction of components of Annual Real Losses and components of night flow

- 1994: FAVAD (Fixed and Variable Area Discharges) concept for analysis and prediction of diverse pressure:leakage rate and pressure:consumption relationships

- 1999: Development of 'best practice' performance indicators for operational management of Real Losses, including a formula to predict Unavoidable (technical minimum) real losses on a system-specific basis, allowing for key parameters

- 2000: International Best practice Water Balance and Performance Indicators 
- 2002: Introduction of $95 \%$ confidence levels to Water Balance and other calculations.

The methods are summarised in the International Report on Water Losses Management and Techniques presented at the 2001 IWA Berlin Congress (Lambert, 2002) and a series of articles by members of the current IWA Water Losses Task Force in 'Water21' magazine between May 2003 and December 2004.

\section{The Four Component Approach to Managing Real Losses}

The practical approach for operational management of Real Losses is summarised in Figure 1, where the volume of Current Annual Real Losses (CARL) for a distribution system, calculated using the IWA best practice water balance, is represented by the large box. The CARL volume exhibits a continual trend to increase as new leaks and bursts occur, and the distribution system deteriorates with age, but it can be constrained and reduced by an appropriate combination of pressure management; speed and quality of repairs; active leakage control (to locate unreported leaks and bursts); and pipeline and assets management.

The lowest technically achievable annual volume of Real Losses, at the current operating pressure, is the Unavoidable Annual Real Losses (UARL), represented by the small box. System-specific volumes for UARL can be calculated using a formula developed by the first IWA Water Losses Task Force (199699), based on length of mains, number of service connections, customer meter location (relative to property line) and average pressure (Lambert et al, 1999). The UARL formula can be applied to systems with more than 5000 service connections, more than 25 metres pressure, and more than 20 service connections per $\mathrm{km}$ of mains.

It is not usually economic to achieve the UARL, unless water is very scarce and/or very expensive. The Economic Level of Real Losses usually lies somewhere between the CARL and the UARL (very few systems internationally achieve demonstrable economic real losses)

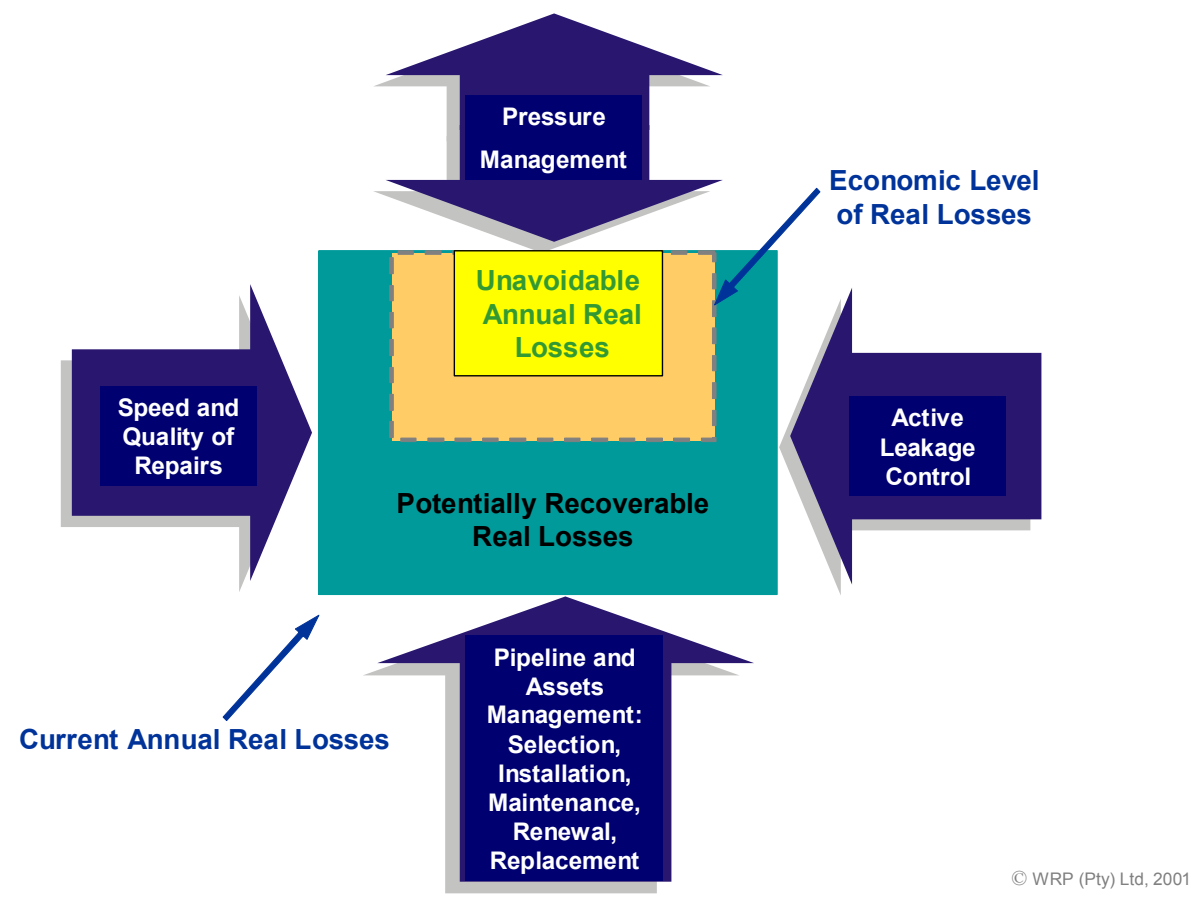

Figure 1: The Four Components Approach to Management of Real Losses

Although Figure 1 appears static, management of Real Losses is, in practice, a continual battle to limit the tendency of CARL to increase as time passes, using an appropriate combination of all four management components. The Best Practice performance indicator for the technical efficiency of management of Real Losses, at the current operating pressure, is the Infrastructure Leakage Index (ILI), which is the non-dimensional ratio of CARL divided by UARL. 
ILIs have now been calculated for several hundred systems worldwide, and typically range from close to 1.0, to 15 or more (McKenzie and Lambert, 2004), although occasionally figures in excess of 100 have been identified. Less than 20 Utilities worldwide have been identified, to date, as achieving an ILI in the range 1.0 to 1.5, which represents a very high technical standard of Real Losses management. Economic leakage levels in England and Wales appear to be in the range 1 to 3. (Lambert, McKenzie and Waldron, 2004).

To allow for errors and assumptions in the Water Balance and associated data, 95\% confidence limits have been increasingly used in such calculations; a most useful feature of such calculations is that the item of 'input' data with the highest variance is the item where efforts should be concentrated if the 95\% confidence limits of the 'output' items is to be reduced. Figure 2 shows, for an Australian system, the CARL (with 95\% confidence limits) compared with the Unavoidable Annual Real Losses, and the Unavoidable Background leakage (FASTCALC, 2004).

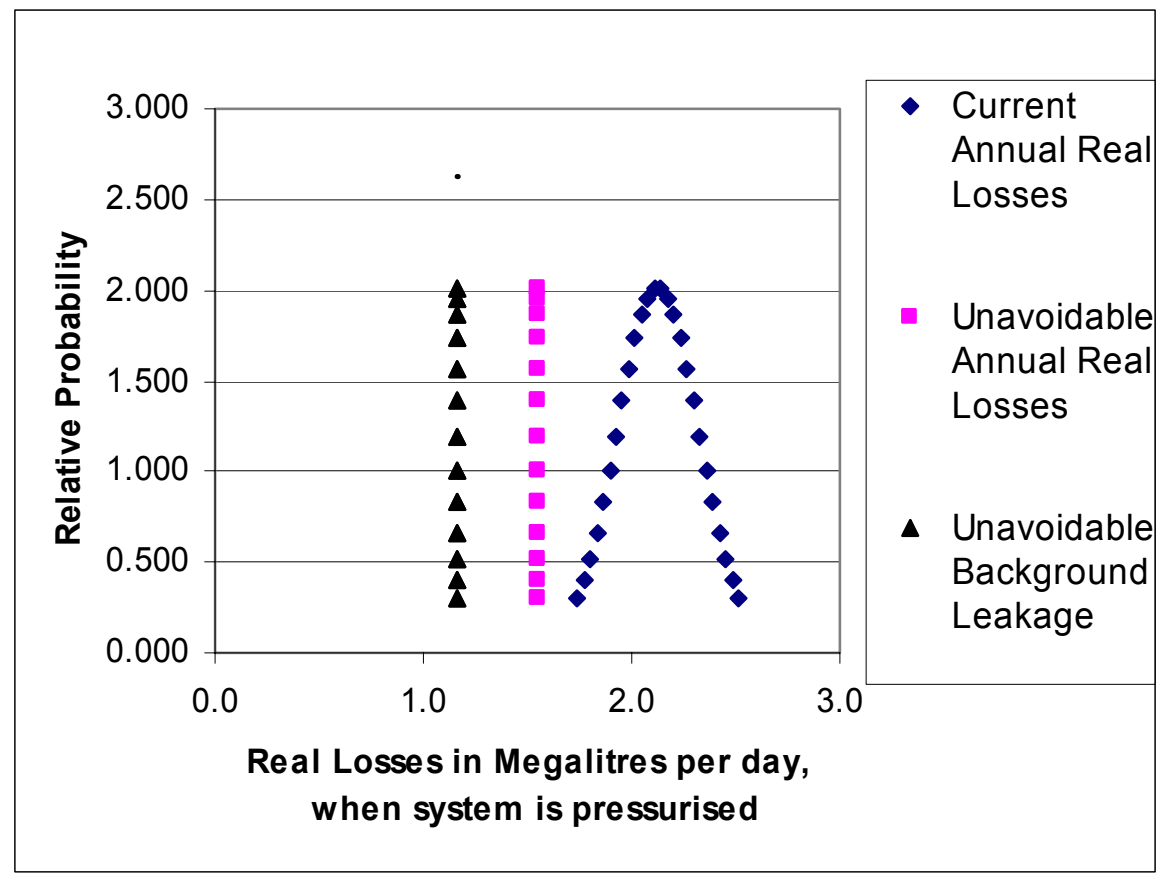

Figure 2: Current Annual Real Losses (2001/02), Unavoidable Annual Real Losses, and Unavoidable Background Leakage for an Australian Distribution System.

Experience of many such calculations demonstrates that, for well managed systems with low leakage and reliable metering of inputs and consumption, it is very difficult to achieve $95 \%$ confidence limits of less than $+/-15 \%$ for the Real Losses volume calculated from a 'top-down' water balance (e.g. EPA\&Wide Bay Water, Manual No 3, 2005). Additional assessments of the Real Losses volume from night flow measurements and/or BABE component analysis are therefore recommended as best practice (Alegre et al, 2000). Night flows are also likely to be beneficial in identifying districts with high leakage; and a basic BABE component analysis model will assist in identifying the most effective strategies to reduce real losses.

The methodology for assessment and technical management of Real Losses, as broadly described above, is now promoted by Water Losses Task Force members, recommended by National organisations in South Africa, Australia, New Zealand and North America, and has been used by consultants and international funding agencies in more than 20 countries. The methodologies used for calculating CARL and UARL are proving to be both robust and practical (particularly when $95 \%$ confidence limits are included in the calculations). 
A stated key objective of the present Water Losses Task Force (Liemberger and Farley, 2004) is 'to develop a quick and practical method for calculating economic intervention (for active leakage control to locate unreported leaks and bursts), and short-run economic leakage level (SRELL).

Clearly, there is little point in attempting to calculate, or to achieve, an economic level of real losses for a particular system, unless the Utility commits to undertaking (to an appropriate extent) all four components of real losses management shown in Figure 1. Pending the development of a method for calculating economic leakage levels, a practical approach successfully used by Utilities such as Malta Water Services Corporation, and Halifax Regional Water Council (Canada) has been to identify and implement a mixture of initiatives within the 4 components that individually have the highest benefit:cost ratio, or shortest payback period. When no further economically viable initiatives can be identified, it can be reasonably assumed that an economic leakage level has been achieved -although it must be recognised that the economic leakage level will change with time.

Economic leakage levels can also be predicted using BABE component analysis models; several components of real losses need to be calculated, namely:

- background (undetectable) leakage from small non-visible inaudible leaks

- volumes lost from reported leaks and bursts

- volumes lost from unreported leaks and bursts, with an economic intervention frequency.

Component Analysis models developed for large systems in the UK require knowledge of the number and types of unreported leaks and bursts that occur, on average, each year. As most Utilities internationally do not undertake any active leakage control, this type of information on typical numbers of unreported bursts is usually not available outside the UK. A simpler approach is required to encourage more Utilities to commence an active leakage control policy, and to assess:

- for small systems, the economic frequency of intervention to find unreported leaks

- for large systems, the economic \% of the system that should be inspected each year

- an appropriate annual budget for such activities

- the economic annual volume of unreported real losses, corresponding to the economic intervention frequency.

In the remainder of the paper, a simple method for calculating these parameters on a system-specific basis is proposed, based on sonic leak detection by regular survey (sounding fittings, noise loggers or similar techniques). A recent example applying the method in Northern Italy is shown, for a small system with no permanent night flow measurements.

This approach, with enhancements such as 95\% confidence limits for all parameters and predictions, has now been incorporated into software for calculations of various Economic Leakage Levels. This software (Fastcell) is currently being tested in Italy, Australia and the UK.

\section{ECONOMIC INTERVENTION THEORY}

\section{Natural Rate of Rise of Leakage.}

Figure 3 (from the UK) shows how the night flow in part of a distribution system can gradually increase with time, because of 'unreported' leaks and bursts, even though all 'reported' leaks and bursts are promptly repaired. Repairs of unreported leaks found during a recent active leakage control intervention have been completed by week 16 . The nightflow is checked against estimates of customer night use and background leakage, to ensure no significant bursts remain. The average rate of rise that then occurs is system-specific and irregular, being influenced by several local factors; but the average rate of rise can be assessed from periodic night flow measurements at times of year when industrial and irrigation use at 
night is considered to be minimal.

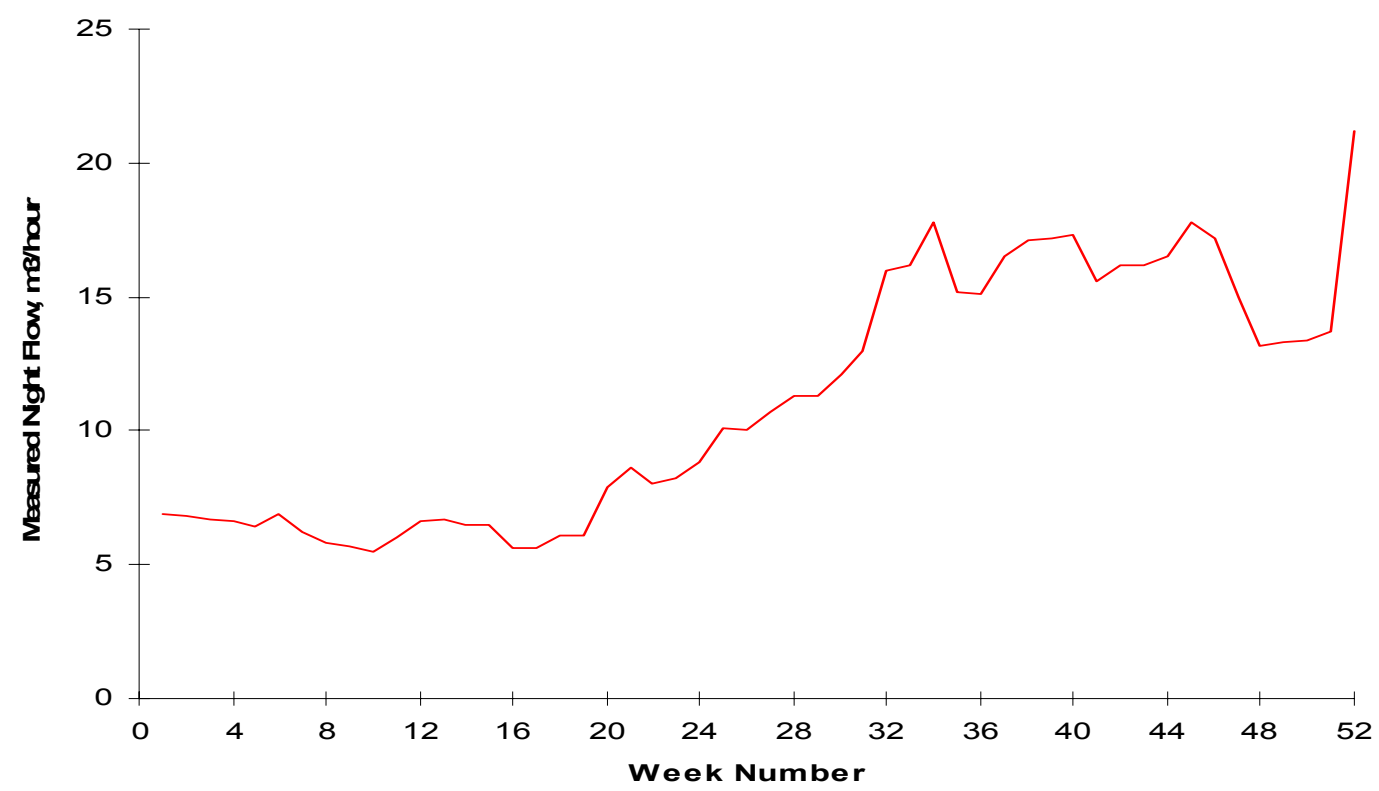

Figure 3: Natural rate of rise of unreported leakage

Figure 4 shows this situation in a more general form. Over time Ta days, the night flow rises from Qo to $\mathrm{Q} 1$, an increase of Qu. If the average night pressure is Po when Qo is measured, and P1 when Q1 is measured, then if Po and P1 are significantly different, it will be necessary to correct Qo (multiply Qo by $\mathrm{P} 1 / \mathrm{Po}$ ) before proceeding with the calculation. Also, night leakage rates in $\mathrm{m} 3 /$ hour must be multiplied by an appropriate Night-Day Factor (NDF), which relates leakage rates at night to average daily leakage rates, allowing for 24-hour variations in pressure.

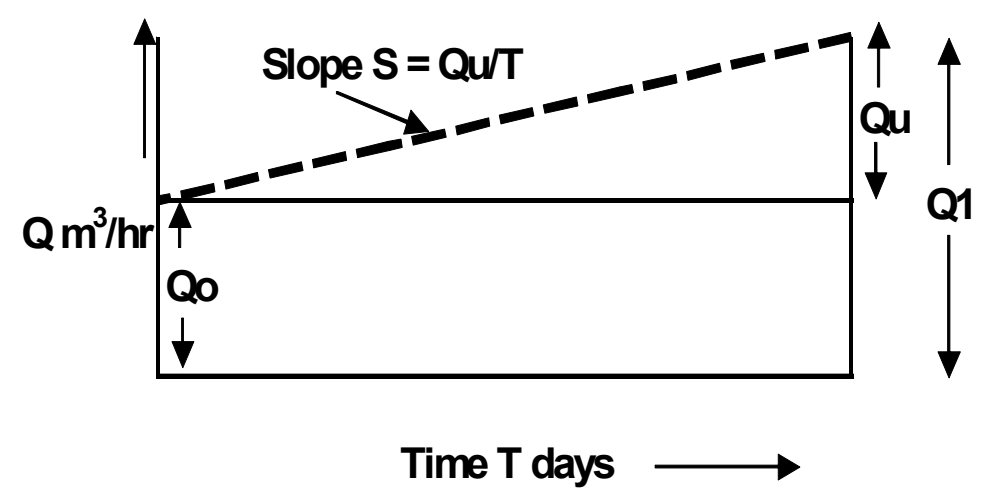

Figure 4: General simplified form of Rate of Rise of Unreported Leakage vs Time

Once Qo has been corrected for pressure (if necessary), and Qu converted to $\mathrm{m}^{3} /$ day by application of a Night-Day Factor, the average rate of rise of unreported leakage can be calculated as

$$
\mathrm{S}\left(\mathrm{m}^{3} / \text { day/day }\right)=\mathrm{Qu} \times \mathrm{NDF} / \mathrm{T}
$$

After time $\mathrm{T}$, the volume of the triangle representing the unreported leakage is

$$
\mathrm{V}\left(\mathrm{m}^{3}\right)=0.5 \times \mathrm{T} \times \mathrm{ST}=0.5 \times \mathrm{S} \times \mathrm{T}^{2}
$$

If the marginal cost of water is MAC Euro $/ \mathrm{m}^{3}$, the value of the unreported leakage volume $\mathrm{V}$ at time $\mathrm{T}$ is

$$
\text { MAC } x \mathrm{~V}=\mathrm{MAC} \times 0.5 \times \mathrm{S} \times \mathrm{T}^{2}
$$

\section{Economic Frequency of Intervention (EIF)}

Using assumptions similar to economic stock control theory, it can be shown (Lambert et al, 1998), that 
the economic frequency of intervention occurs when the cost of a 'full system' intervention CI (excluding repair costs) equals the value of the unreported leakage volume MAC $\mathrm{x} V$. Thus the economic period between interventions (Te in days) occurs when

$$
\mathrm{CI}=\mathrm{MAC} \times \mathrm{V}=\mathrm{MAC} \times 0.5 \times \mathrm{S} \times \mathrm{Te}^{2}
$$

or

$$
\mathrm{Te}(\text { days })=(\mathrm{CI} /(\mathrm{MAC} \times 0.5 \times \mathrm{S}))^{0.5}
$$

If $\mathrm{S}$ is expressed in $\mathrm{m}^{3} /$ day per year, rather than $\mathrm{m}^{3} /$ day per day, then

$$
\begin{aligned}
& \text { Te }(\text { days })=(\mathrm{CI} /(\mathrm{MAC} \times 0.5 \times \mathrm{S} / 365))^{0.5} \\
& \quad \text { and } \\
& \mathrm{Te}(\text { months })=(0.789 \times \mathrm{CI} /(\mathrm{S} \times \mathrm{MAC}))^{0.5}
\end{aligned}
$$

Economic Percentage of System (EP): For large systems, if Te exceeds 1 year, it is preferable to intervene in an appropriate percentage of the system each year, rather than to wait and then intervene in the whole system once every few years. The economic percentage of the system (EP) that should be inspected each year is:

$$
\mathrm{EP} \%=100 \times(12 / \mathrm{Te})
$$

Where Te is in months

The Annual Budget for Intervention (ABI) is then calculated as

$$
\mathrm{ABI}=\mathrm{EP} \% \times \mathrm{CI}
$$

Economic Annual Volume of Unreported Real Losses (EAVURL): When an economic percentage (EP) of the system is being inspected each year:

$$
\mathrm{EAVURL}=\mathrm{ABI} / \mathrm{MAC}=\mathrm{EP} \times \mathrm{CI} / \mathrm{MAC}
$$

Quick and Practical Predictions From the above, it can be seen that several important technical and financial parameters can be quickly predicted, if the marginal cost (MAC) and rate of rise of unreported leakage (S) are estimated (and assumed to be constant), and an intervention cost (CI) is specified. It is not essential to know the typical average annual numbers and locations of unreported leaks within the distribution system (e.g. on mains, hydrants, valves, service connections etc) - although such data, if available, can of course be used to improve the calculations. It can also be noted that the calculations of Te, EP\% and EAVURL:

- are not highly sensitive to moderate random errors in CI, MAC and S, due to the 0.5 exponent

- are independent of the currency units used, due to use of the ratio CI/MAC

\section{APPLYING THE METHOD}

\section{Case Study}

A small district in Northern Italy; with 900 service connections; $16 \mathrm{~km}$ of mains; with no permanent inflow metering (Fantozzi \& Lambert, 2004).

Cost of an ALC intervention (using noise loggers) $=$ Euro 4000

Marginal cost of water MAC $=0.11$ Euros $/ \mathrm{m}^{3}$

Night flow measured 14 Feb 2002 after intervention and leak repairs $=10.8 \mathrm{~m}^{3} / \mathrm{hr}$

Night flow measured again 10 April 2004 (786 days later) $=18.0 \mathrm{~m}^{3} / \mathrm{hr}$ (assumed same pressure) 
Average rate of rise $\mathrm{S}=18.0-10.8=7.2 \mathrm{~m}^{3} / \mathrm{hr}$ in 2.15 years $=3.35 \mathrm{~m}^{3} / \mathrm{hr} /$ year If $\mathrm{NDF}=24 \mathrm{hrs} /$ day, $\mathrm{S}=3.35 \mathrm{~m}^{3} / \mathrm{hr} /$ year $\mathrm{x} 24=80.4 \mathrm{~m}^{3} /$ day $/$ year Economic Intervention Frequency Te $($ eqn $5 b)=(0.789 \times 4000 /(80.4 \times 0.11))^{0.5} \quad=18.9$ months Economic Percentage of system EP\% $=12$ months $/ 18.9$ months $\quad=63 \%$ of system each year Annual Budget for Intervention $\mathrm{ABI}=\mathrm{EP} \% \mathrm{x} \mathrm{CI}=63 \%$ x 4000 Euros $=$ Euros 2540 per year Econ. Annual Vol Unrep Real Losses $=$ EP x CI/MAC $=63 \%$ x 4000/0.11 $\quad=22909 \mathbf{~ m}^{3} /$ year

\section{User friendly Predictions}

By expressing CI and S in terms of 'per service connection' or 'per km of mains', equations for Te, $\mathrm{EP} \%$, ABI and EAVURL can be presented in many different units and graphical formats, eg. Fig 5 below for predicting economic intervention. In the Italian example, CI is $4.44(=4000 / 900)$ Euros/service connection, MAC is $0.11 \mathrm{Euros} / \mathrm{m}^{3}$, so CI/MAC $=4.44 / 0.11=40 \mathrm{~m}^{3} /$ service connection. For a rate of rise $\mathrm{S}$ of 89 litres/service conn/day/year $\left(=80.4 \mathrm{~m}^{3} /\right.$ day/year x $\left.1000 / 900\right)$, the graph predicts economic intervention approximately every 18 months (compared to 18.9 months as calculated above). Limitations of space preclude additional examples, but the shape of such graphs is most helpful in obtaining a general overview of how the interaction between $\mathrm{S}$ and the ratio $\mathrm{CI} / \mathrm{MAC}$ influences Te, $\mathrm{EP} \%, \mathrm{ABI}$ and EAVURL.

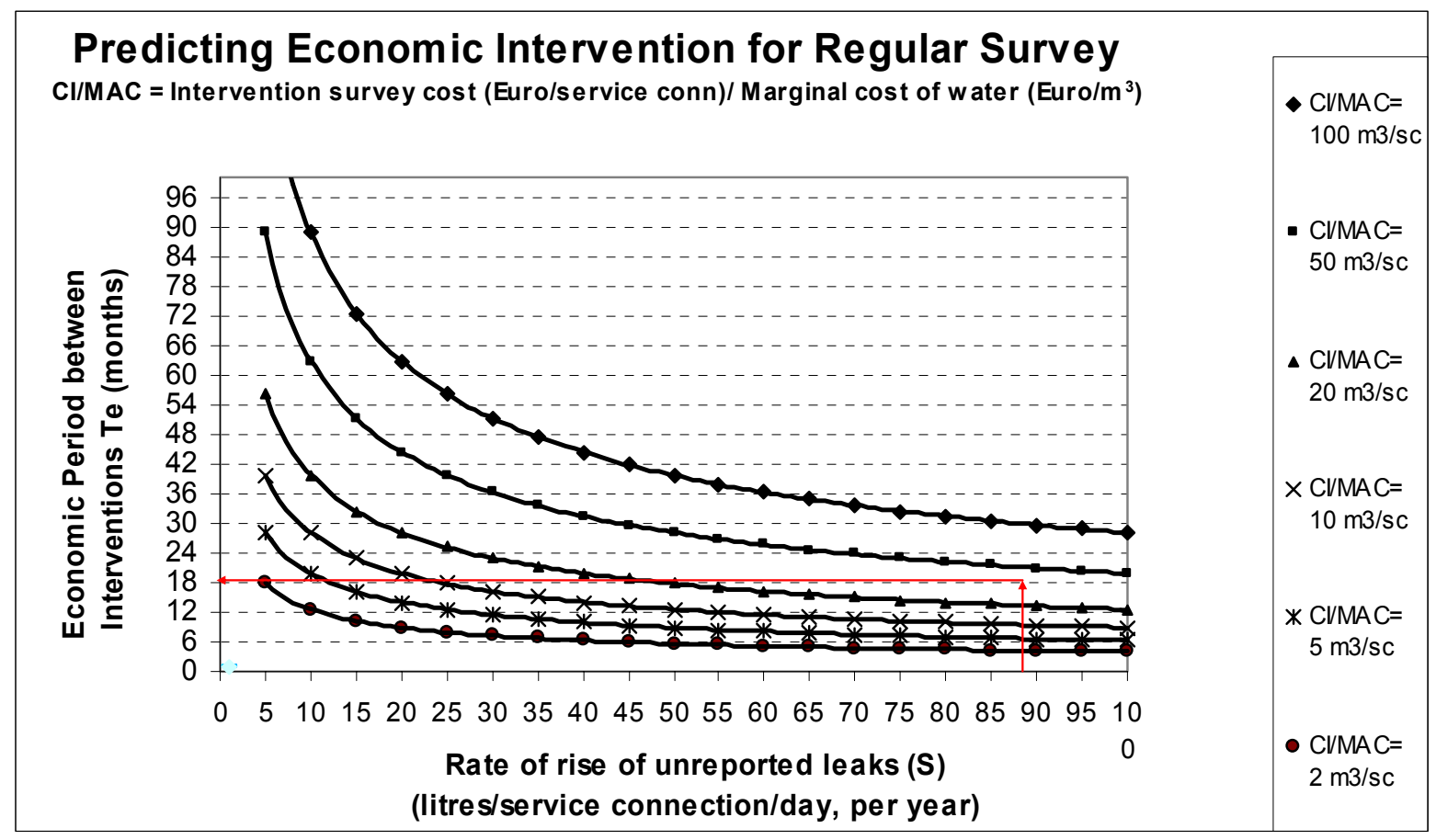

Figure 5: Graph for predicting economic frequency of intervention Te

\section{Application to large systems}

The basic approach described above can also be applied (with modification as necessary) to larger systems. For large Utilities that do not undertake active leakage control, an initial approximate estimate of the rate of rise of unreported leakage $(S)$ for the whole system could be based on the rate of increase in Current Annual Real Losses (from Annual Water Balances) over a period of several years. An initial 'whole system' estimate of Te and EP can then be made; and the approximate annual budget (ABI) and EAVURL estimated (preferably with confidence limits, using software).

Then, the $\mathrm{S}$ values for each part of the system can be assessed by attributing typical flow rates to the leaks and bursts found during successive interventions, and the Te, ABI and EAVURL assessed on an ongoing basis for each part of the system. This approach is currently being applied to leak detection data done on a 'block by block' basis in a large North American city. 


\section{CONCLUSIONS}

Conclusions of this paper are as follows:

- Over the last decade, a technically robust set of methods and concepts have been developed for assessment and management of Non-Revenue Water and its components

- These methods, adopted in an ever-increasing number of countries, are being successfully promoted internationally by members of the IWA Water Losses Task Force (WLTF) .

- Use of $95 \%$ confidence levels in water balance calculations is a notable practical step forward

- Existing UK methods for assessing Economic Leakage Levels, which require continuous night flow measurements in small districts, are currently not applicable in most international situations

- The WLTF is seeking a simple method for calculating Economic Intervention Frequency and Short Run Economic Leakage Levels for application to large and small systems internationally

- A simple method of assessing economic intervention frequency for regular survey, intervention budgets etc is needed to encourage more Utilities to implement ongoing active leakage control

- The method presented in this paper requires only three parameters - average rate of rise of unreported leakage, marginal cost of water, and cost of intervention

- It is assumed that marginal cost of water and rate of rise of unreported leakage are approximately constant for any individual system or sub-system

- The ratio of Cost of Intervention to Marginal Cost of Water is a key parameter, and is independent of currency units used..

- The approach is simple, versatile and should be capable of wide application, particularly with the use of $95 \%$ confidence limits in the calculations

- A paper covering further developments in this topic has been submitted for presentation at a WLTF 'Leakage 2005' Seminar in Halifax, Nova Scotia, in September 2005.

\section{ACKNOWLEDGEMENTS}

To the many members of the Water Losses Task Force who have contributed to the development of these methodologies; but with particular thanks to John Morrison, David Pearson and Stuart Trow.

\section{REFERENCES}

Lambert, A. (2002). 'Water Science and Technology:Water Supply, Vol 2 No 4,1-20, 2002.

McKenzie Dr R \& Lambert, A, 2004: Best Practice Performance Indicators: a practical approach. Water21, August (2004).[http:/iwapublishing.com/template.cfm?name=w21aug04]

Lambert, McKenzie and Waldron, (2004). ILIs over four continents. Demand Management Bulletin No 6, October 2004..[Available on line at: www.environment-agency.gov.uk/savewater]

Fastcalc,(2004). International software to calculate IWA Water Balance and Performance Indicators with 95\% confidence limits. Contact ILMSS Ltd and Studio Fantozzi for details

Queensland Environmental Protection Agency and Wide Bay Water (in press): Manual 3, The Economics of Water Loss Management'. ISBN 072429495 3. Part of series 'Managing and Reducing Losses from Water Distribution Systems'.

Alegre H et al, (2000). Performance Indicators for Water Supply Services. IWA Manual of Best Practice. ISBN 900222272

Liemberger R \& Farley M: The Water Loss Task Force: recent highlights and future events. Water21, December 2004. .[Available on line at: http:/iwapublishing.com/template.cfm?name=w21dec04]

Lambert et al, 1998: Managing Water Leakage: Economic and Technical Issues. Financial Times Energy. ISBN 1840830115

Fantozzi M \& Lambert A: 'Experiences in application of IWA approach to small Water Networks in Italy', H2O Conference on 'Water Losses Management', Ferrara, Italy, 2004. 